\title{
ESTUDIOS
}

\section{SOBRE MAQUINAS E INSTRUMENTOS (II): EL MUNDO DEL OJO EN LA OBRA DE E.T.A. HOFFMANN*}

\author{
Luis Montiel
}

Universidad Complutense. Madrid

\section{RESUMEN}

Continuando con lo desarrollado en el trabajo precedente se estudia en éste el conjunto de problemas vinculados al tema de la visión que suscita la mera existencia del cuerpo del autómata. Los ojos del androide y, sobre todo, las reacciones suscitadas por la contemplación de estas máquinas de aspecto humano, son objeto de la reflexión de Hoffmann desde una postura que parece instalarse en la noción goetheana de un «mundo del ojo»-Welt des Auges- Desde esta perspectiva se despliega así mismo una aguda crítica del abordaje instrumental de la realidad natural tal como, desde el siglo XVII, venía planteándose en la ciencia.

PALABRAS CLAVE: Medicina y literatura. Autómatas. Microscopio. E.T.A. Hoffmann. Goethe.

\section{ON MACHINES AND INSTRUMENTS (II): THE WORLD OF THE EYE IN THE WORK OF E.T.A. HOFFMANN}

\section{ABSTRACT}

Continuing with the subject of the previous work, this article considers the whole series of problems connected to the question of the vision provoked by the mere existence of the body of the automaton. The eyes of the android and, above all, the reactions aroused by looking at these human-shaped machines are the object of Hoffman's reflections, from a viewpoint apparently firmly set within the Goethean concept of the "world of the eye» - Welt des Auges. Similarly, there is also an in-depth analysis from this same perspective of the instrumental approach to natural reality as it had been perceived in science since the seventeenth century.

* Proyecto HAR 2008-04899-C02-02/HIST. 
LUIS MONTIEL

KEY WORDS: Medicine and literature. Automata. Microscope. E.T.A. Hoffmann. Goethe.

\section{INTRODUCCIÓN: LA NOCIÓN GOETHEANA DE UN WELT DES AUGES}

«Beruf ist mir zu rühmen höhers»; «es mi vocación celebrar lo superior», sostiene Hölderlin en su poema a la Princesa Augusta de Homburg. Hoy hago mía esta declaración al introducir en el título de este escrito el de una bella obra de Heinrich Schipperges ${ }^{1}$ que ha orientado mi mirada según un Kunst des Schauens, un arte del mirar, al que me confío para abordar con alguna pretensión de novedad la obra de Hoffmann precisamente desde la perspectiva del sentido de la vista; perspectiva, como ya adelanté, complementaria e indisociable de la adoptada para estudiar la figura del autómata ${ }^{2}$. Pero, en honor a la verdad, y para la mejor comprensión de cuanto sigue, hay que señalar que la idea de un Welt des Auges, de un «mundo del ojo», es más antigua. Goethe fue quien acuñó esta locución ${ }^{3}$, quien planteó este concepto, si bien no desde la nada, sino recuperándolo del acervo de la filosofía de la naturaleza de los physiologoi jonios en su monumental y polémica Farbenlehre (1810), con la que se propuso nada menos que refutar la óptica de Newton. Sabido es que su propósito quedaría sin efecto, pero a cambio instituyó como dominio de estudio la fisiología y la psicología de la percepción ${ }^{4}$. La tesis «presocrática» de

1 Schipperges, H. (1978), Welt des Auges. Zur Theorie des Sehens und Kunst des Schauens, Freiburg, Herder.

2 Montiel, L. (2008), Sobre máquinas e instrumentos (I): el cuerpo del autómata en la obra de E.T.A. Hoffmann, Asclepio, LX (1), pp. 151-176.

3 Aparece por primera vez en una carta a Friedrich Schiller fechada el martes 15 de noviembre de 1796, refiriéndose al placer que le producen las observaciones que realiza sobre la naturaleza; observaciones en que predomina el sentido de la vista, pues la naturaleza es, «si así puede decirse, el mundo del ojo, que se crea mediante la figura y el color (...) Sólo en medida menor necesito los medios auxiliares de los otros sentidos, y todo razonamiento se transforma en una especie de representación». DöRR, V.C., OELLERS, N. (Hrsg.) (1998), Johann Wolfgang Goethe Sämtliche Werke. Briefe, Tagebücher und Gespräche. 40 Bände, Band 4 (31) Frankfurt am Main, Deutscher Klassiker Verlag, pp. 259-260.

4 Schipperges, H. (1978), pp. 126-128 ; GuSDORF, G. (1993), Le romantisme, vol. I, Paris, Payot, pp. 197-213 ; BöHME, G. (1987), Is Goethe's Theory of Color Science? En AMRINE, F., ZuCKer, F.J., WheEler, H. (eds.), Goethe and the Sciences. A Re-appraisal, Berlin, Springer, pp. 147-173; BöHME, H. (2003), Die Metaphysik der Erscheinungen. Teleskop und Mikroskop bei Goethe, Leeuwenhoek und Hooke. En Schramm, H., SCWARTE, L., LAZARDIG, J. (Hrsg.), Kunstkammer, Laboratorium, Bühne. Schauplätze des Wissens im 17. Jahrhundert, Berlin, De Gruyter, pp. 359-396; DuQUE, F. (1999-2000), «Alles ist sie mit einem 
Goethe es que los colores «están» en el ojo, porque el ojo tiene naturaleza lumínica; de otro modo no podría percibir la luz y cuanto ella manifiesta. De manera que, por más que pueda existir un mundo fuera de nosotros, el mundo que nosotros percibimos es y será siempre un «mundo del ojo», Welt des $A u$ ges. Más adelante habré de volver sobre la teoría goetheana de la visión. De momento regresemos al que debe ser el punto de arranque de este trabajo, el reconocimiento de que el problema de la percepción está íntimamente vinculado al del cuerpo como autómata tal como fue formulado en el estudio precedente. Y ambos son, como también adelanté, el resultado de un movimiento, casi de una inercia de la conciencia occidental moderna que la poesía, antes que la filosofía y la historia del pensamiento, percibió agudamente.

\section{CONTEXTO: El PROGRAMA ILUSTRADO DEL PRÍNCIPE PAHPNUTIUS Y ALGU- NAS DE SUS CONSECUENCIAS}

Hoffmann fue uno de los primeros, si no el primero, en comprender que ambos temas, el del cuerpo del autómata - o mejor, el del cuerpo como autómata - y el de la realidad de lo que se percibe a través de los ojos, no eran sino dos aspectos de un mismo problema; un problema acuciante, angustioso, unheimlich ${ }^{5}$, que se cernía sobre el ser humano moderno amenazando su propia conciencia de sí. Su celebérrimo relato Der Sandmann - El hombre de la arena-, es la mejor prueba de ello, y habrá de ocupar buena parte de este estudio; pero no es el único de sus escritos en los que el de la mirada y el mundo del ojo se convierte en problema filosófico y antropológico de rango superior. También entendió que la amenaza no había surgido de la nada, sino que se trataba de un evento históricamente comprensible que, a su modo, expuso en uno de sus últimos relatos extensos, Klein Zaches gennant Zinnober

\footnotetext{
Male». La actitud de Goethe en la naturaleza, Estudi General. Revista de la Facultat de Lletres de la Universitat de Girona, 19-20, pp. 83-103; KRATZ, O. (1988), Goethe und die Naturwissenschaften, München, Kallwey; FARULLI, L. (2005), L'occhio di Goethe. Arte, natura, teoria del colore. En Frigo, G.F., Simili, R., Vercellone, F., Engelhardt, D., VON (2005), Arte, scienza e natura in Goethe, Torino, Trauben, pp. 113-126; MACKENSEN, L.V. (2005), Luce e buio nella teoria del colore di Goethe. En Frigo, G.F., Simili, R., Vercellone, F., EngelHARDT, D., VON (2005), pp. 247-255.

5 Este calificativo, bien conocido por todo lector familiarizado con la obra hoffmaniana y/o con la de Sigmund Freud, será, inevitablemente, el núcleo de uno de los asuntos más polémicos de los que habré de ocuparme en el presente texto.
} 
(El pequeño Zaqueo llamado Cinabrio). En esta desaforada sátira ${ }^{6}$, cuyo argumento se le ocurrió a su autor en el curso de uno de los intensos accesos febriles de una enfermedad, probablemente relacionada con la que le llevó a la muerte ${ }^{7}$, trabamos conocimiento con un cierto príncipe de un cierto estadículo alemán de esos que, como piezas de un rompecabezas, constiuían la Germania anterior a la Revolución Francesa, o de alguno similar superviviente de la aventura napoleónica. Este príncipe, de nombre Paphnutius y un tanto limitado de caletre, escucha embobado los consejos de su primer ministro, un burgués imbuido del espíritu de Las Luces como tantos de sus contemporáneos, que intenta convencer a su amo de la conveniencia de modernizar su Estado. La conversación entre ambos constituye una prodigiosa muestra del arte hoffmaniano de la sátira:

¡Sire! ¡La gran hora ha sonado! ¡Un reino luminoso se alza desde el poderoso Caos! ¡Sire! ¡Del pecho y de la garganta de vuestro vasallo más fiel brotan suplicantes las mil voces del pobre pueblo desdichado! ¡Sire! ¡Introducid la Ilustración!

A estas palabras de su ministro responde el príncipe, sinceramente emocionado, que hará imprimir un edicto que habrá de hacerse público en todas las paredes del reino anunciando que «desde este mismo momento queda implantada la Ilustración». Con devota paciencia, el ministro le explica que una tarea tan importante no puede llevarse a cabo sin un concienzudo trabajo preliminar:

Antes de llevar adelante la Ilustración, es decir, antes de talar los bosques, hacer navegables los ríos, hacer que broten patatas, mejorar las escuelas de los pueblos, plantar acacias y chopos, antes de hacer cantar a los niños sus oraciones de la mañana y de la noche a dos voces, antes de cuidar las carreteras y de inocular la vacuna, es indispensable expulsar del estado a todas esa gentes que profesan opiniones peligrosas, que no escuchan nunca la voz de la razón y seducen al pueblo con toda suerte de necedades (...): [las hadas], enemigas de la Ilustración [y] causantes de que el reino esté sumergido en el oscurantismo más completo. Se entregan a la peligrosa práctica de lo maravilloso y no temen expandir, bajo el nombre

6 Véase lo que luego se dirá al respecto de Meister Floh.

7 Lo sabemos por un testimonio de su amigo Hitzig, a quien Hoffmann se lo comunicó en el curso de una de las visitas de aquél a su lecho de enfermo. GüNZEL, K. (1979), E.T.A. Hoffmann Leben und Werk in Briefen, Selbstzeugnissen und Zeitdokumenten, Düsseldorf, Claasen, pp. 357-358. 
de poesía, un veneno sutil que vuelve a las personas absolutamente ineptas para servir a la causa de la Ilustración ${ }^{8}$.

Si bien la primera parte de este parlamento resulta un tanto simplificadora, tópica incluso, pues no alude más que al bien conocido pragmatismo de la mentalidad ilustrada, al ejercicio de la razón instrumental — término éste que ha devenido de uso común, que tomo en préstamo a J. Habermas - la segunda es claramente subversiva, pues pone de manifiesto la voluntad de control a la que hice referencia en mi escrito anterior. Según el ministro, la Ilustración no está al servicio de los hombres, sino a la inversa, y la poesía distrae de este servicio hasta el extremo de hacer inútil para él a quien, como una enfermedad, la padece. Por ello hay que tomar medidas urgentes, previas a cualesquiera otras, y desde luego represivas: hay que expulsar del país a las hadas. Y si alguna quiere quedarse, cosa que incluso resultaría conveniente al alto ideal político profesado por el ministro, deberá necesariamente, como diríamos hoy, aceptar un proceso de reconversión hacia una tarea útil para la cosa pública, por ejemplo, «tejer calcetines para el ejército en caso de guerra» ${ }^{9}$. La acción épico-satírica arranca de la situación creada por esta maniobra policial, cuando un hada que se decide por la clandestinidad bajo las respetables tocas de madre abadesa de un convento decide adoptar al pequeño aborto cuyo nombre da título a la narración y origen a mil delirantes aventuras, que tienen por objeto mostrar cómo la locura - la locura razonante - puede hacerse dueña de un Estado sin hadas y sin poesía (Fig. 1). Pero no es éste el objetivo del presente trabajo, de modo que debemos abandonar a Klein Zaches hasta mejor ocasión, no sin advertir que con su historia se abre el breve período satírico-grotesco ${ }^{10}$ de Hoffmann, clausurado por la muerte cuatro años más tarde. De momento su mención debe servirnos para contextualizar en perspectiva historicocultural los relatos de que vamos a ocuparnos a continuación.

$8 \mathrm{http}: / /$ gutenberg.spiegel.de/?id=5\&xid=609\&kapitel=3\&cHash=18212119ce2\#gb_found (Consultada el 4-VII-2007) (p. 2). Como en el artículo precedente citaré por la edición on-line del Proyecto Gutenberg y, cuando exista, por una edición española de calidad. En este caso, así como en el de Meister Floh, al que me referiré más tarde, carecemos de una edición en nuestro idioma.

9 Ibíd.

10 No pretendo establecer tipología ni cronología alguna de cuño crítico literario. Sencillamente me limito a señalar que con Klein Zaches, y luego con Meister Floh, el escritor se lanza a tumba abierta - en más de un sentido - a la crítica del mundo en el que vive empleando para ello la caricatura que acentúa los rasgos grotescos. Véase más adelante lo que se dirá sobre Meister Floh. 


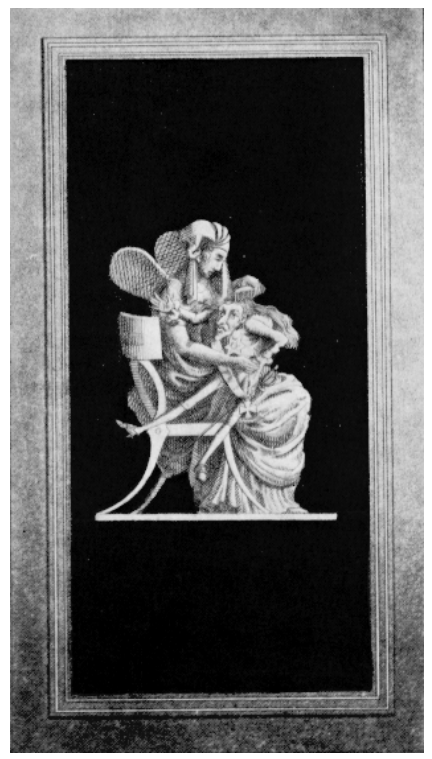

Fig. 1. Portada de Klein Zaches, diseñada por Hoffmamnn, que representa la acción mágica — a través del peinado- del hada Rosabelverde sobre su pupilo Klein Zaches.

\section{LOS OJOS DEL AUTÓMATA}

Regresemos, pues, al primero de los relatos que nos ocuparon en el trabajo precedente, Los autómatas. Antes incluso de acudir al oráculo del turco, Ludwig declara sin ambages el desagrado que le producen los ingenios mecánicos que copian la figura humana, a los que califica de

auténticas imágenes de la muerte viva o de la vida muerta, no tanto porque estén construidas a imagen del hombre, cuanto porque imitan como un mono lo humano ${ }^{11}$.

Es decir, como ya quedó señalado, porque esa similitud con lo humano es poco más o menos la misma que presentan los cadáveres: les falta el espíritu. Y para Ludwig esto se pone de relieve principalmente en los ojos. Las pala-

11 http://gutenberg.spiegel.de/etahoff/serapion/serap331.htm (Consultada el 20-II-2007) (p. 31 de dicha edición). HofFMANN, E.T.A. (1988), Los autómatas, en Los hermanos de San Serapión, II, (Ed. de Celia y Rafael Lupiani y Julio Sierra), Madrid, Anaya, p. 70. 
bras que siguen a su anterior declaración lo muestran con claridad, suministrando además argumentos para la reflexión sobre lo Unheimliche que anunciaba al principio:

Ya de pequeño solía escapar llorando cada vez que me llevaban a un museo de cera, y aún hoy sigo sin poder entrar en un gabinete de esos sin sentir una sensación horriblemente inquietante —unheimlichen grauenhaften - Cada vez que veo sobre mí las miradas fijas, muertas, cristalinas, de todos esos potentados, famosos héroes, asesinos y bribones, me gustaría gritar, en palabras de Macbeth: «¿Qué hacéis ahí, mirándome con ojos ciegos?» Y estoy convencido de que la mayoría de los hombres comparten conmigo, aunque no en el elevado grado que en mi domina, esta inquietante —unheimliche - sensación, pues se puede comprobar que la mayor parte de la gente que está en un gabinete de figuras de cera habla únicamente en susurros (...) Y ello no ocurre por respeto a los altos personajes, sino únicamente por la presión de lo inquietante, lo horrible, — des Unheimlichen, Grauenhaften - que provoca necesariamente ese pianissimo en los espectadores ${ }^{12}$.

Ludwig termina su parlamento declarando que lo más angustioso para él son «los movimientos humanos de las figuras muertas, imitados y producidos mecánicamente», entre los que señala los «giros de ojos». A ellos se refiere de inmediato Ferdinand, quien, compartiendo, como sabemos, en lo esencial el juicio de Ludwig, observa una actitud menos hostil hacia estos artefactos, que considera meros dispositivos orientados a la distracción del espectador:

sus giros de cabeza y movimientos de ojos están ahí, con toda seguridad, únicamente para dirigir nuestra atención sobre esa parte en la que no se encuentra la clave del secreto ${ }^{13}$.

Como sabe el lector del relato hoffmaniano - o en su defecto de mi artículo precedente - esta interpretación racionalista de Ferdinand tendrá escasa, si

12 Ibíd. Lejos de mí proponer como definitivas las traducciones que doy a los términos alemanes del texto. Por eso los incluyo en la cita.

13 http://gutenberg.spiegel.de/etahoff/serapion/serap331.htm (p. 31). HoFFMANN, E.T.A. (1988), p. 71.

El buen sentido de Ludwig da, desde luego, en el clavo, aunque ello tenga escaso interés para el mensaje, mucho más sutil y ambicioso, que Hoffmann pretende transmitir en su relato. Años más tarde, el más célebre constructor de autómatas y empresario de variétés basadas en su exhibición, Robert-Houdin, señaló en sus escritos teóricos y autobiográficos que el éxito de cualquier espectáculo de ilusionismo se basaba precisamente en la habilidad de distraer la atención del espectador de lo esencial. ARIDJIS, C. (2005), Topografia de lo insólito. La magia y lo fantástico literario en la Francia del siglo XIX, México, Fondo de Cultura Económica, pp. 135-136. 
no nula relevancia en el relato, pues ambos amigos compartirán un mismo interés por lo que pueda ocultarse detrás del artificio mecánico, que, como intenté demostrar, tendría más que ver con el sorprendente mundo recién descubierto del magnetismo animal que con la hipótesis del hombre-máquina. Pero el tema de los ojos del autómata, así como el de los humanos, volverá a aparecer desempeñando un papel central en la obra probablemente más estudiada de las de Hoffmann: El hombre de la arena.

Buena parte de la culpa, o del mérito, de que este Nocturno haya alcanzado tal relevancia crítica la tiene el escrito de Freud titulado Das Unheimliche ${ }^{14}$ (1919), lo que me da ocasión para comenzar a saldar una vieja deuda con mi amigo Hoffmann, consistente en restituir a su relato el sentido que él mismo quiso darle después de que no pocos se hayan empeñado durante casi un siglo en adaptarlo contra viento y marea al lecho de Procusto freudiano ${ }^{15}$.

Aunque pueda parecer una obviedad, comencemos por el principio. Dado que el relato se presenta a modo de intercambio epistolar con tardías incursiones del autor, cuanto sabemos de la infancia de Nathanael se debe a su propia pluma, y esto ya introduce un factor de incertidumbre nada desdeñable, evidentemente buscado por Hoffmann. Con todo, en esa parte de su biografía no es posible discernir nada sugerente de patología mental alguna, y la descripción de la escena alquimista protagonizada por su padre y Coppelius presenta un aspecto muy realista, incluso - y sobre todo- si se tiene en cuenta que se trata de una escena estremecedora vista con los ojos de un niño de diez años. Es imposible saber si se trata de un relato documental, de una fantasía o de un delirio. Nada en la narración permite pronunciarse al respecto; tal es, sin duda, la intención de Hoffmann. Por otra parte la ausencia de

14 Este término ha sido traducido al español por los editores de la obra de Freud como «siniestro» - Ludovico Rosenthal, López Ballesteros - y como «ominoso» —Echeverri- Basándose en su etimología el filósofo Félix Duque le ha dado el significado, grávido, para mi gusto, de sentido, de «inhóspito». Cfr. ConDE, A.C., Lo siniestro enroscado a la palabra. Lenguaje y extrañamiento a través de la lectura de Lo siniestro de Freud, http://www.ucm.es/info/especulo/ numero33/siniestr.html (Consultada el 18-VII-2007).

15 Lejos de mí la pretensión de pasar por el salvador de la princesa encantada, pues desde hace algún tiempo se alzan voces, incluso procedentes del entorno psicoanalítico, contra la violencia ejercida por Freud sobre el texto de Hoffmann. Entre nosotros destacan los trabajos de Jesús González Requena, particularmente —en el tema que nos concierne- éste: GonZÁLEZ ReQuenA, J. (1997), Emergencia de lo siniestro, Trama y fondo, 2, 51-77. Por otra parte, dada la envergadura del tema, creo que me veré obligado a dedicar otro trabajo al estudio más pormenorizado de este asunto, ocupándome en éste sólo de los aspectos más claramente relacionados con el tema elegido. 
información, por más que pudiera ser indirecta, sobre aquel episodio en los textos de Clara y Lothar no nos autoriza a tratarlo como un síntoma. Con el material de que disponemos, lo único que podemos hacer es dar crédito a lo que Nathanael refiere, a saber, que en medio de una operación espagírica realizada por los dos adultos, cuyo objetivo parece ser la fabricación de un homúnculo, que él contempló a escondidas, se echan en falta los ojos como expresión de la verdadera vida, y que Coppelius parecía decidido a arrancar los de Nathanael — sin metáfora alguna - en el empeño de lograr aquello que se le escapaba en su pretensión prometéica. La causa de la muerte del padre - la explosión del laboratorio-, que confirmaría la versión de Nathanael acerca de los secretos trabajos alquímicos de su progenitor y el abogado, tampoco es desmentida ni matizada por quienes deberían saber si se trata o no de un hecho real. Según esto Nathanael ha vivido una situación en la que se ha sentido amenazado por la pérdida de los ojos - insisto: de los ojos - para que el producto de una hybris pudiera disponer de ellos. Creo que éste no es un dato baladí: no se trata sólo de perder un órgano - como ocurriría en el caso de la castración ${ }^{16}$-, sino de que este órgano es robado para dárselo a otra criatura. Hasta donde yo sé, la angustia de castración freudiana opera según un patrón en el que sólo hay pérdida, pero no ganancia ajena, y más concretamente de un tercero. También aquí hay que volver sobre lo prometéico, pues el gigante mitológico no roba el fuego de los dioses para apagarlo, sino para dárselo a los hombres. Por último, la ceguera de Nathanael, de haberse producido, no sería comparable a la de Edipo, pues ni habría tenido carácter autopunitivo ni se habría agotado - al menos según los designios de Coppelius - en la mera ablación.

La confidencia de este trágico recuerdo se ha visto motivada por la aparición en la vida actual del estudiante Nathanael del italiano vendedor de barómetros e instrumentos ópticos Giuseppe Coppola, cuyo apellido trae a la memoria del joven el odiado y temido de Coppelius ${ }^{17}$. Ya antes de que nada suceda esta similitud en los nombres, y la consiguiente sospecha de que pueda tratarse de la misma persona, han inquietado al portagonista, lo que hace comprensible su sentimiento de pánico cuando el vendedor expone sobre la

16 Como es sabido, Freud sostiene en su texto que la evisceración de los ojos es en este caso un equivalente de la castración, remitiéndose al complejo de Edipo.

17 Se ha señalado con profusión el hecho de que tales apellidos evocan nociones que tienen un peso extraordinario en el relato; así Coppelius es muy similar a «copela», "vaso de figura de cono truncado, hecho con cenizas de huesos calcinados, y donde se ensayan y purifican los minerales de oro o plata» (DRAE) - lo que, a través de la química, nos remite a la alquimia- y Coppola hace pensar en «coppo», en italiano, órbita del ojo. 
mesa de su habitación de estudiante su muestrario de gafas, presentándolas en su deficiente alemán como «sköne Oke», «hermosos ojos»» ${ }^{18}$. Hago notar que antes de mostrarlas, el espanto suscitado por la declaración del italiano de que, además de barómetros, vende «sköne Oke», se ha adueñado ya de Nathanael, sin duda a causa de la reminiscencia de la vivencia traumática infantil - que no parece haber sido reprimida en modo alguno- a la que ya he hecho referencia. Pero no es menos interesante detenerse sobre lo que viene después: bajo el impacto de esta impresión, lo que el estudiante contempla sobre su mesa son «mil ojos [que] miraban y se estremecían fijándose en [él]». Aquí encontramos de nuevo la mirada fija - starre - que despertaba en Ferdinand el sentimiento de lo Unheimliche en los gabinetes de figuras de cera: la mirada artificial, a la que le falta la vida, que sólo de manera imperfecta intenta encubrir el movimiento mecánico de los ojos de algunos autómatas, como el famoso turco. No son ojos amputados — si se quiere, «castrados»-, sino ojos fabricados los que producen un sentimiento que, en este caso, recibe el nombre de Entsetzen - horror, espanto, pavor - siendo en este caso «gespenstisch» - fantasmal - el calificativo que se aplica a tales «ojos».

Es hora ya de dar entrada al autor cuya interpretación puso a Freud, según éste mismo reconoció, sobre la pista del sentimiento de lo Unheimliche en Hoffmann: el psiquiatra Ernst Jentsch. En un texto publicado en 1906 en una revista psiquiátrica ${ }^{19}$ Jentsch se aproximaba al tema de lo Unheimliche especialmente desde el punto de la psicología — con algún apoyo en la etnología- y de la psicopatología, aunque mencionando en un punto las creaciones hoffmanianas. Según parece Freud tuvo noticia, inevitablemente parcial, acerca de los relatos de Hoffmann precisamente a través de este artículo ${ }^{20}$. El caso es que Jentsch dedica menos de tres líneas al escritor, y por cierto nada explícitas: «E.T.A. Hoffmann ha empleado repetidamente con éxito esta maniobra psicológica en sus relatos fantásticos» ${ }^{21}$. Por alguna razón que desconocemos Freud se lanza de lleno sobre el Sandmann, mientras que un cono-

$18 \mathrm{http}: / /$ gutenberg.spiegel.de/?id=5\&xid=604\&kapitel=5\&cHash=61f05a2d182\#gb_found (Consultada el 16-VII-2007) (p. 5). HofFMAnN, E.T.A. (1987), El hombre de la arena. En LuPIANI, C. y LuPIANI, R. (eds.), Nocturnos, Madrid, Anaya, pp. 43-44.

19 Jentsch, E. (1906), Zur Psychologie des Unheimlichen, Psychiatrisch-Neurologische Wochenschrift, pp. 22, 195-198 y 23, 203-205.

20 Gordo, J. (2003), El concepto de «lo siniestro» en la obra de Freud (Tesis doctoral, p. 29 , n. 4). En esta misma nota se menciona otra posible fuente para el interés del fundador del psicoanálisis en la obra de Hoffmann: El doble, de Otto Rank (1914). En cualquier caso parece que Freud estaba lejos de conocer de primera mano la rica producción de nuestro autor.

21 JENTSCH (1906), p. 203. 
cedor de la obra de Hoffmann, a la vista de lo sostenido por Jentsch en las páginas precedentes, relativas a las figuras de cera y a los muñecos animados, habría pensado mucho más en Los autómatas. No es extraño que a Freud le suenen a hueco algunos asertos de Jentsch que él mismo cita en Das Unheimliche; pero es que él está intentando aplicarlos a Der Sandmann, cuando lo que Jentsch tiene in mente es el texto precedente. Por ejemplo:

Es bien conocida la incómoda impresión que con gran facilidad produce en algunas personas la visita a gabinetes de figuras de cera, panópticos y panoramas ${ }^{22}$.

Apenas hace falta recordar al lector el testimonio de Ferdinand sobre los gabinetes de figuras de cera recientemente transcrito ${ }^{23}$. Por otra parte, cuanto Jentsch menciona en su escrito referente a los autómatas - que no es poco, desde luego- puede perfectamente aplicarse a la Olimpia del Sandmann, pero con aún mayor razón a los autómatas del relato homónimo. Lo cual, por otra parte, es extremadamente razonable, pues es evidente que la figura de Olimpia no aparece porque sí en la historia de Nathanael, sino que es descendiente directa de los androides del profesor X que aparecen en el relato que forma parte de Los Hermanos de San Serapión. Me temo que Freud se vio conducido a un mal paso por su desconocimiento de la obra de Hoffmann así como por la decisión de Jentsch de plantearse un trabajo sobre lo Unheimliche, tema que inevitablemente debía interesar a aquél, en el que menciona el nombre del escritor. Posiblemente Freud pensó que el relato de Hoffmann se ocupaba singularmente de este asunto, cuando lo cierto es que el término mismo no tiene un protagonismo extraordinario en él: aparece seis veces, mientras que otros términos sinónimos, a veces asociados a él del modo que hemos visto, lo hacen con notable reiteración: schrecklich, 3; entsetzlich, 15; grausam y derivados, 16. Por otra parte, el sentimiento que designa fácilmente podría encontrarse, y tal vez corregido y aumentado, en otros relatos como Das öde Haus - La casa vacía (1817) - en el que, por más señas, no hay autómatas ni ojos arrancados, aunque sí extrañas visiones.

Es importante recordar que los ojos de Nathanael no son los únicos amenazados. En el poema por él escrito, Coppelius arranca los ojos a Clara, los

22 JeNTSCH (1906), p. 198.

23 Como ha señalado un estudioso de la obra de Hoffmann, también en Der Sandmann juega el artista con la misma incertidumbre, convirtiéndola en recurso literario para provocar el sentimiento de lo Unheimliche: Cuando la muñeca Olimpia es destrozada por Spalanzani y Coppola, sus ojos sangran (al menos eso es lo que percibe Nathanael). DRUX, R. (1986), Marionette Mensch. Ein Metaphernkomplex und sein Kontext von E.T.A. Hoffmann bis Georg Büchner, München, Fink, p. 84. 
arroja contra el pecho de Nathanael y le arrastra hacia el fuego en medio de una danza frenética. En ese momento Clara pide a su prometido que la mire, asegurando que aún conserva sus ojos, y que de este modo puede salvarle. Pero cuando lo hace, Nathanael cree ver los ojos de la muerte. Este poema del que sólo conocemos el argumento tiene una gran importancia que Freud no le reconoce ${ }^{24}$, por más que su interpretación gire en torno al simbolismo de los ojos, o más exactamente, de su mutilación. Con él como pretexto, o si se prefiere, como revelador - en la acepción fotográfica del término - muestra Hoffmann el verdadero nudo del relato, al permitirnos contemplar las reacciones de ambos personajes, Clara y Nathanael, frente a esta producción del inconsciente — pulida, desde luego, mediante una ulterior elaboración más consciente ${ }^{25}$ - del protagonista. En efecto, cuando Nathanael concluye su redacción y lo lee para sí mismo en voz alta "sintió - escribe Hoffmann - horror y exclamó: ¿De quién es esa voz horripilante? ${ }^{26}$. Pero luego se convence a sí mismo de que se trata solamente de un poema logrado. Lo que, sin embargo, queda claro es que la distancia establecida por la lectura en alta voz le provoca una primera reacción de espanto y de enajenación. Aunque consciente mientras trabajaba, sólo ahora se da cuenta de que ha dejado hablar a su inconsciente, así como del peligro que entraña ese mensaje. Cuando por fin se lo lee a Clara, la reacción de ésta es equiparable, aunque configurada en torno a un patrón diferente, propio de la personalidad que, desde el comienzo, Hoffmann le ha atribuido, señalándola con la elección de su nombre: la muchacha le pide que arroje al fuego «ese cuento absurdo... sin sentido... loco». La respuesta de Nathanael, mientras la abandona, «indignado» es: «iMaldita autómata sin vida!» ${ }^{27}$.

En este punto se instala, a mi parecer, lo Unheimliche en el mundo del protagonista. Ante la emergencia de sus más íntimos fantasmas, la sensata muchacha le recomienda buscar la salud a través de la negación; Nathanael se siente incomprendido, y a la postre no amado, y la descubre entonces como «autómata sin vida»; pero en su sufrimiento — en su locura - la sustituirá por una auténtica autómata: la criatura de Spalanzani y Coppola. Mala solución, a

24 Gordo, J. (2003), p. 55.

25 «Mientras escribía este poema, Nathanael estuvo muy tranquilo y concentrado. Corregía, limaba cada uno de los versos y, habiéndose sometido al rigor del metro, no descansó hasta que todo engarzaba con precisión y su sonido fue puro». http://gutenberg.spiegel.de/ $? \mathrm{id}=5 \& \mathrm{xid}=604 \& \mathrm{kapitel}=5 \& \mathrm{cHash}=61 \mathrm{f05a} 2 \mathrm{~d} 182 \# \mathrm{gb} \_$found (p. 5, p. 40 de la ed. esp.).

$26 \mathrm{http}: / /$ gutenberg.spiegel.de/?id=5\&xid=604\&kapitel $=5 \& \mathrm{cHash}=61 \mathrm{f} 05 \mathrm{a} 2 \mathrm{~d} 182 \# \mathrm{gb}$ _found (p. 5, p. 40 de la ed. esp.).

$27 \mathrm{http}: / /$ gutenberg.spiegel.de/?id $=5 \& \mathrm{xid}=604 \& \mathrm{kapitel}=5 \& \mathrm{cHash}=61 \mathrm{f} 05 \mathrm{a} 2 \mathrm{~d} 182 \# \mathrm{gb}$ found (p. 5, p. 41 de la ed. esp.). 
todas luces, que nos muestra que, aunque poseedor de un cierto grado de razón, el joven lleva en sí el germen de una enfermedad aún más peligrosa que la mantenida, de forma larvada, por el fantasma de Coppelius: un narcisismo morboso.

En el momento en que este rasgo se manifiesta por completo el Hoffmann inquietante deja lugar, por más que en contados momentos, al satírico; por ejemplo cuando, ante el recuerdo de la muñeca que apenas hace algo más que contemplarle - aparentemente, pues sus ojos no tienen vida - y suspirar de tanto en tanto, Nathanael, emocionado, profiere: «iOh, tú, maravilloso y profundo ser! (...) Sólo tú, tú eres la única persona que me entiende por completo! $\gg^{28}$. Y poco antes le ha hecho decir, utilizando un símil que pertenece de lleno al Welt des Auges: «¡Oh, tú, espíritu profundo en el que se refleja toda mi existencia! $»^{29}$. De pasada anotaré que esta frase - y no sólo ella- autorizaría una interpretación del relato con la ayuda de la teoría psicológica de C.G. Jung, pues da toda la impresión de que lo que aquí se dirime es la angustiada búsqueda del anima por el protagonista ${ }^{30}$. En esta perspectiva lo Unheimliche se nos presenta, además, bajo una nueva luz, pues el propio Nathanael utiliza el término al explicar a su amigo Sigmund sus sentimientos: «Ya puede Olimpia ser unheimlich para vosotros (...) Sólo en su amor me encuentro a mí mismo» ${ }^{31}$.

Pero lo que nos interesa en este contexto es algo bien diferente: el cuerpo del autómata, el Welt des Auges y su mutua relación. Sólo en esta perspectiva hemos de ocuparnos de unos ojos en los que toda la existencia de Nathanael - y cualquier otra cosa - puede reflejarse por el mero hecho de que no son ojos, sino esferas de cristal magistralmente coloreadas por la mano del inquietante Coppola. Esos ojos no tienen mundo, en el sentido goetheano, aunque el mundo entero pueda reflejarse en ellos. Pero sí hay un Welt des Auges en Nathanael, y la mayor prueba de ello es que, en su caso, Olimpia es, también, ocasionalmente unheimlich, pero sólo para el sentido del tacto. Cuando, en el baile, toca su mano, experimenta un sentimiento que, esta vez, el autor califi-

$28 \mathrm{http} / /$ gutenberg.spiegel.de/ $/ \mathrm{id}=5 \& \mathrm{xid}=604 \&$ kapitel=6\&cHash=61f05a2d182 (p. 6, p. 51 de la ed. esp.).

$29 \mathrm{http} / /$ gutenberg.spiegel.de/ $\mathrm{id}=5 \& \mathrm{xid}=604 \& \mathrm{kapitel}=6 \& \mathrm{cHash}=61 \mathrm{f05a} 2 \mathrm{~d} 182$ (p. 6, p. 49 de la ed. esp.).

30 Hace años publiqué una interpretación semejante de otro relato de Hoffmann, El caldero de oro. MonTIEL, L. (1995), Un cuento de hadas sobre la vida del inconsciente: El caldero de oro, de E.T.A. Hoffmann, Jano, XLVIII (1115), pp. 39-44.

$31 \mathrm{http} / /$ gutenberg.spiegel.de/?id=5\&xid=604\&kapitel=6\&cHash=61f05a2d182 (p. 6, pp. 50-51 de la ed. esp.). 
ca precisamente con el problemático término; pero al mirarla, sobre todo a través del anteojo de Coppola, sus ojos se animan y parecen arrojar rayos lunares $^{32}$. El mundo del ojo del protagonista, el suyo propio, incomparable, es quien, para su mal, anima a la muñeca de madera.

De este modo es él quien entroniza el triunfo de la técnica; pues si Coppelius y el padre de Nathanael no fueron capaces de crear vida mediante la alquimia, y si aquél intuyó que la única posibilidad restante se encontraba en la mecánica ${ }^{33}$, Spalanzani y Coppola han conseguido esta copia cibernética que deslumbra a la mayoría, y que alcanza incluso a suplantar a su modelo real para ese nuevo hombre que surge de la revolución tecnológica, o que al menos se desarrolla a partir de ella de manera incomparable: el narcisista. A mi juicio, el atisbo verdaderamente genial de Hoffmann en este punto radica en la superación del punto de vista más común, el que se fija en el creador prometéico, para desplazarse hacia el destinatario ideal del producto: del técnico productor al público consumidor. Pues, en el Sandmann, este tipo de creador ha encontrado por primera vez un cliente. Más aún: el cliente por antonomasia; el ser humano que quiere reconocerse en la máquina, que quiere una máquina que se le parece para que le devuelva de sí mismo la imagen deseada. Ironía excelsa, acierto psicológico mayúsculo de Hoffmann, es en este caso el poeta romántico quien, en lugar de vender tópicamente su alma al diablo, desea para sí un autómata sobre el que proyectarla. En nombre de un ideal torcido de la comprensión, de la comunicación entre dos seres, escoge el desierto y el eco. Asistimos al triunfo del hombre máquina. Pero, ¿quién es el hombre máquina? ¿la criatura cibernética o el ser humano que dice ante ella: «esto soy yo?»34

32 Gendolla, P. (1992), Anatomien der Puppe. Zur Geschichte der Maschinenmenschen bei Jean Paul, E.T.A. Hoffmann, Villiers de l'Isle Adam und Hans Bellmer, Heidelberg, p. 169.

33 V. Montiel (2008), p. 174.

34 Evidentemente no se trata del triunfo definitivo. Hoffmann nos está mostrando el nacimiento de un hecho cultural de extraordinaria relevancia, pero, como tal nacimiento, se trata aún de un fenómeno incipiente, incluso lacunar. Aunque también de manera irónica - lo que demuestra la escasa confianza que Hoffmann tenía en la capacidad de respuesta de sus contemporáneos - el escritor describe las reacciones que el ataque de locura de Nathanael al descubrir a Olimpia desarticulada entre las manos de su creador provoca en la sociedad de la ciudad universitaria: «La historia del autómata había arraigado profundamente en sus almas y, de hecho, surgió una profunda desconfianza hacia las figuras de aspecto humano. Y para convencerse por completo de que uno no se había enamorado de una muñeca de madera, varios amantes exigieron a la amada que bailara y cantara sin conservar el compás, que durante las lecturas bordara e hiciera punto, jugase con el perrito, etc., pero sobre todo que no sólo 
Unheimlich. Desde luego. ¿Cómo no va a ser unheimlich un relato en el que se nos habla no de la castración — real o simbólica — sino de la aniquilación del alma en el espejo mágico del simulacro, y de la entronización definitiva del autómata como rey de la creación, como pareja soñada, buscada y adorada del ser humano de carne y hueso que se siente insatisfecho de su condición? Pero esta pregunta nos conduce a otro lugar, de regreso, podríamos decir: de nuevo al Welt des Auges. Pues Nathanael ha encontrado lo que buscaba, la compañera ideal, con la ayuda de un instrumento óptico: el catalejo que le vendió Coppola, que parece animar mágicamente la figura de Olimpia, de modo que el estudiante Sigmund, amigo del protagonista — quien no observa la realidad a través de instrumento alguno - no puede comprender el delirio de éste y debe limitarse a compadecerle y a ofrecerle su ayuda cuando llegue el momento, que no puede sino temer, en que los devaneos psíquicotecnológicos del joven le lleven a la catástrofe. Pues la locura le acecha, y se presenta de hecho al menos dos veces en el relato ${ }^{35}$, de modo que, a riesgo de parecer exagerado, me atrevería a conceder a este personaje hoffmaniano una dignidad ejemplarizante similar a la de Don Quijote; en efecto, tal vez nos encontremos ante el Don Quijote de la era tecnológica.

Más, mucho más habría que decir sobre este texto prodigioso. Pero, en la perspectiva elegida, quizá convenga hacer aquí un alto, no para finalizar el viaje sino para emprender otro camino que nos conduzca al objetivo buscado. Nathanael encuentra a Olimpia, y continúa luego buscándola apasionadamente, con la ayuda de un anteojo. Cinco años más tarde, nuestro guía y narrador nos situará de nuevo ante el mundo del ojo y de los instrumentos ópticos, esta vez con la intención de ajustar cuentas. Si en Der Sandmann Nathanael es una especie de Don Quijote, ahora será Hoffman quien asumirá un aspecto del personaje de nuestro hidalgo, contendiendo con sus particulares molinos de viento. Adentrémonos en el mundo mágico de Maese Pulga.

escuchara, sino que de vez en cuando dijese algo, de forma que esas palabras mostraran un pensamiento previo. De resultas de ello la unión amorosa de muchos se fortaleció y se convirtió en más estimulante, mientras que otros, por el contrario, se separaron en silencio»».

http://gutenberg.spiegel.de/?id=5\&xid=604\&kapitel $=7 \& \mathrm{cHash}=61 \mathrm{f} 05 \mathrm{a} 2 \mathrm{~d} 182 \# \mathrm{gb}$ found (p. 7, p. 55 de la ed. esp.).

35 Cuando arremete, presa de furia, contra Spalanzani al ver que entre él y Coppola han destruido la muñeca, y debe ser reducido y encerrado en un asilo, y evidentemente al final, cuando intenta asesinar a Clara y finalmente se suicida. 


\section{UNA AVENTURA EN EL MUNDO DEL OJO}

Escrito si no en su lecho de muerte, sí al menos en el lecho que prácticamente sólo abandonaría para ser enterrado, Meister Floh (Maese Pulga), se publicó, después de ser mutilado por la censura, en el año en que falleció Hoffmann, 1822. En este encantador relato fantástico, especie de Bildungsroman a contrapelo, pues representa casi lo contrario que el protomodelo del género $^{36}$, el Wilhelm Meister de Goethe, el protagonista, Peregrinus Tyss, se nos presenta desde las primeras páginas como un individuo extraordinariamente inmaduro ${ }^{37}$, o más exactamente, replegado sobre sí mismo para no verse obligado a entrar en la madurez. El lector lo encuentra celebrando la Nochebuena en la solitaria mansión que, junto con un floreciente negocio que prácticamente marcha solo, ha heredado de sus padres, en un actitud descaradamente infantil: a sus treinta y seis años, como todas las navidades, espera en silencio, en la oscuridad del gabinete anexo al comedor, a recibir la señal que le permitirá salir a la sala iluminada para, lleno de ardiente júbilo, recoger del pie del abeto decorado con velitas los regalos que poco antes ha comprado para sí mismo y que luego repartirá entre niños pobres, y cenar luego junto a dos sillas vacías —no así los platos frente a las que se sitúan- destinadas a sus padres, con quienes incluso simula hablar.

36 El propio Hoffmann lo denominó Märchen. El título completo del relato es Meister Floh. Ein Märchen in sieben Abenteuer zweier Freunde. El término alemán Märchen suele traducirse al español como cuento fantástico, o de hadas, o folklórico, y algo de todo ello lleva en sí el vocablo alemán. Como puede verse, el planteamiento de Hoffmann es bastante más modesto que el que cabe suponer a una «novela de formación». Por otra parte, una estudiosa reciente de esta obra ha discutido también el acierto de Hoffmann al adscribir al género literario del cuento fantástico la obra que nos ocupa, afirmando que «Meister Floh no es un Märchen, sino más bien una sátira grotesca con aspecto de Märchen en la tradición menipea». MAYER, P. (2006), E.T.A. Hoffmanns Meister Floh: eine groteske märchenhafte Satire, Goethezeit Portal: URL: $<$ http://www. goethezeitportal.de/db/wiss/hoffmann/floh-groteske-satire_mayer.pdf $>$ (Consultada el 12-IV-2007). Cita en p. 42. (Menipo - Ss. IV-III a.C- fue un filósofo de la escuela cínica que se valía de fábulas para zaherir a los filósofos a los que desdeñaba).

37 Entre los datos suministrados al respecto en las primeras páginas hay uno que, además, nos permite asociarlo - aunque de manera antitética, como demostrará el relato- al tema del autómata. En su primera infancia tardó mucho en comenzar a hablar e incluso a relacionarse con los adultos, de manera que su madre, alarmada y entristecida, le comparaba a una «muñeca inanimada», y el autor, transcribiendo las opiniones de dichos adultos, le llama «niño-autómata». Pero será un muñeco — un Arlequín - el primer objeto — ¿el primer personaje? — que le arranque gestos y expresiones de júbilo. De este modo reconquista el escritor, a través del ánimo infantil y del juego, la figura de la copia humana, maltratada en el contexto del que nos estamos ocupando. 
Verdaderamente se trata de alguien a quien le hace falta una Bildung, y con urgencia. En todo caso su infantilización es sólo parcial, pues ante determinadas circunstancias no se ha comportado, ni se comportará en adelante como un niño. Por ejemplo, no ha vacilado en perderse para los demás durante un par de años en un viaje, iniciativa ésta nada pueril, que parece haberle llevado al menos hasta la India. Si volvemos la vista a ese modelo de género que es el Wilhelm Meister podríamos decir que al menos nuestro Peregrinus — ¡nótese, además, el significado del nombre! — ha realizado, si es que no está realizando aún en otro sentido, sus Wanderjahre ${ }^{38}$ - años de peregrinaje-, aunque saltándose los Lehrjahre — años de aprendizaje-. Pero ya he dicho que la formación de Peregrinus está planteada a contrapelo. Su aprendizaje vendrá después, y de la mano de un extraño profesor.

La bibliografía sobre Hoffmann es tan gigantesca que ignoro si alguien se habrá planteado ya esta comparación, y si en tal caso habrá caído en la cuenta de que en el título de ambas obras figura en lugar relevante la parabra «maestro», Meister. En el caso de Goethe, Meister es el protagonista aunque, por así decir, deba ganarse a pulso ese título a lo largo de su vida; pero cabría pensar - y este sería un pensamiento bastante goetheano - que desde el principio está predestinado, o más bien dotado para ser un maestro, un señor, pues ha nacido Meister. Le falta, desde luego, a golpe de carácter, realizar cumplidamente aquello para lo que está dotado y así alcanzar su meta. En cambio, nuestro amigo Tyss parece haber nacido para no estarse quieto; para que su vida sea camino, pues es Peregrinus. En su caso la maestría está en otro lugar, otro es el maestro: Meister Floh, Maese Pulga (Fig. 2). Dado que ni siquiera existe una traducción al español de este divertido relato resulta más que nunca necesario dar cuenta de su argumento.

Sabemos ya cómo comienza. Después de la famosa cena, Peregrinus sale a la calle con sus regalos para alegrar la noche de los hijos del encuadernador Lammerhirt y, a través de ellos, la de su padre. Al regreso de casa de éste una atractiva muchacha desconocida que se ha presentado de improviso se desmaya, a lo que el protagonista reacciona tomándola en brazos y llevándola a su casa, inconsciente. Cuando, a la mañana siguiente, la joven se despierta se identifica como Dörtje Elverdink, ahijada de un sabio que responde al nombre, familiar para cualquier historiador de la medicina, de Leeuwenhoek. No tarda en aparecer en escena otro personaje de edad avanzada, realquilado de Peregrinus, cuyo nombre, no menos evocador para el mismo tipo de lector, es

38 El título de la segunda parte de la novela goetheana tiene, como es sabido, por título, Wilhelm Meisters Wanderjahre. 
Swammerdamm. Y curiosamente se muestra muy interesado por la joven que Peregrinus ha recogido.

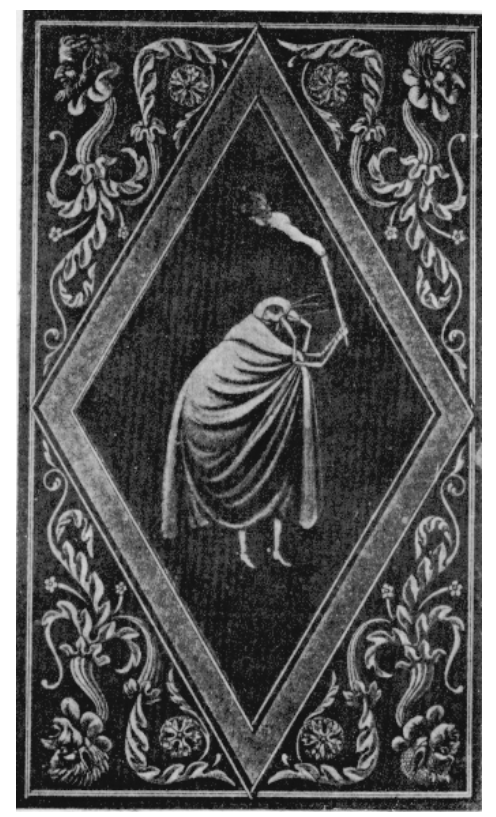

Fig. 2. Imagen de la contraportada — diseñada por Hoffmannde Meister Floh, en la que Maese Pulga se muestra simbólicamente como guía de Peregrinus Tyss.

Leeuwenhoek, convertido - al menos a tiempo parcial - en empresario de espectáculos, presenta en esos momentos en la ciudad uno basado en la observación por medio de lentes y microscopios de diversos insectos ${ }^{39}$. Y precisamente mientras sucede lo anterior, el segundo de los amigos a los que hace mención el título, Georg Pepusch ${ }^{40}$, ve salir en estampida a los espectadores

39 Esta invención de Hoffmann podría presentarse como una prueba más del carácter «teatral» de la nueva ciencia, puesto de relieve por Mandressi para la Anatomía - véase mi artículo precedente - y por Hartmut Böhme precisamente para los trabajos microscópicos de Leeuwenhoek: BÖHME, H. (2003), pp. 386-389.

40 No puede pasarse por alto que, al final del relato, Pepusch se revelará como el cardo Zeherit, perdiendo su apariencia de ser humano. Así resultará que los compañeros de Peregri- 
del gabinete de Leeuwenhoek, espantados por el desorden que en él se ha instaurado por motivos de momento desconocidos y que se traduce en la aparición de auténticos monstruos gigantescos creados por las lentes incontroladas.

Pronto sabemos a qué atenernos pues, en el lecho al que se ha retirado después de dejar descansando a Dörtje, Peregrinus Tyss recibe la sorprendente visita de Maese Pulga, el señor de estos animalillos, cuya fuga del teatro de Leeuwenhoek ha causado el desorden referido. El rey de las pulgas explica a Peregrinus la esclavitud a la que su pueblo y él mismo se han visto sometidos, transformándose contra su voluntad en personajes de circo, vestidos y calzados como militares para que evolucionen obedientemente bajo las lentes de aumento para mayor gloria y lucro de su explotador. Le suplica que le proteja, que no le entregue a sus verdugos, y a cambio le ofrece un regalo: una pequeña lente —una lentilla, en toda la acepción actual del término, pues se fija directamente sobre la córnea- mediante la cual puede contemplar los pensamientos de quienes a él se dirigen.

A estas alturas el lector de este trabajo ya sabe por qué, a pesar de los inescrutables designios del mercado editorial, tiene ante sus ojos al menos un reflejo del relato de Hoffmann. Podría decirse que Meister Floh es, tanto o más que Der Sandmann, una extraordinaria reflexión sobre la mirada y sobre el mundo del ojo, pues prácticamente todo lo que en él se dirima va a girar en torno a dos tipos de lentes: las de los científicos y la que Maese Pulga ha regalado a Peregrinus Tyss ${ }^{41}$. La crítica literaria, sin dejar de lado este aspecto, ha hecho siempre énfasis, y con razón, en otro aspecto del relato de gran repercusión en la biografía de Hoffmann y de no menor interés para la historia

nus en su aventura - en su peregrinar- son una pulga y un cardo, representantes generalmente despreciados de los reinos animal y vegetal.

${ }_{41}$ Añádase a esto que, como agudamente ha observado un autor, todo el relato está construido en torno a la imagen de la camera obscura. MÜLLER, M.M. (2003), Phantasmagorien und bewaffnete Blicke. Zur Funktion optischer Apparate in E.T.A. Hoffmanns Meister Floh, E.T.A. Hoffmann Jahrbuch, 11, 104-121. Estos son, en breve síntesis, los principales argumentos de dicho autor: al comienzo de la narración Peregrinus se encuentra en una habitación a oscuras en la que entra un rayo de luz por debajo de la puerta que comunica con el salón, donde le esperan los productos de su fantasía (p. 104); el protagonista identifica a Dörtje como la princesa Gamaheh solamente cuando la contempla a través del ojo de una cerradura (pp. 116-117); y, a lo largo de todo el relato, Peregrinus es presentado como «el morador de la camera obscura de su propia existencia (p. 108). Y dada su estrecha relación con nuestro tema, conviene no pasar por alto lo que este autor nos recuerda: que la camera obscura fue el modelo explicativo aceptado desde el siglo XVII para explicar científicamente la visión (p. 105), en el marco de esa cosmovisión mecanicista a la que, como estamos viendo, Hoffmann se opone con todas sus fuerzas. 
de Alemania: la escena nocturna en la que Peregrinus transporta en brazos a una Dörtje inconsciente es interpretada torcidamente por un personaje a la vez ridículo y atrabiliario, el Consejero de policía Knarrpanti, en quien era fácil reconocer a su equivalente en la realidad, von Kamptz, gozoso brazo ejecutor de las Resoluciones de Karlsbad y cabeza visible de la persecución de los demagogos. Knarrpantti acusará a Peregrinus de secuestro, sospechando además inconfesables fines sexuales. La sátira, abrumadora, que Hoffmann realiza de éste personaje, unida a su actitud notablemente inconformista en los procesos contra los acusados de demagogia, dará pie a que él mismo sea formalmente acusado y llevado a juicio, aunque no podrá acudir a él a causa del avanzado estado de su enfermedad terminal, viéndose obligado a defenderse a través de un interesantísimo escrito redactado - dicho sea sin retórica- en el lecho del dolor. De hecho será la muerte quien le libre de una sentencia condenatoria, aunque el libro aparecerá censurado.

No entraré, de momento, en más detalles sobre el argumento, pues lo hasta aquí expuesto es lo que conviene a los fines de este trabajo. Tenemos, así, en el planteamiento del asunto a dos personajes cuyos nombres, y no sólo ellos, coinciden con los de dos de los gigantes de la ciencia moderna, especialmente en el campo de la observación de la naturaleza con ayuda de instrumentos ópticos, concretamente el microscopio; y frente a ellos a un animalillo - para muchos un animalejo- que también posee un instrumento capaz de cambiar las circunstancias normales de la visión. Estamos, y pronto veremos hasta qué punto, en el corazón del Welt des Auges.

De los dos científicos es Leeuwenhoek quien desempeña un papel más importante, apareciendo Swammerdam sólo como adversario suyo, sin duda para facilitar el decurso de la acción y, con él, la exposición del mensaje que su creador pretende transmitir. Es Leeuwenhoek quien posee -así puede decirse - a la princesa Gamaheh (Dörtje) y a Maese Pulga, y quien se presenta a Peregrinus como el mismo que está enterrado en el cementerio de Delft, planteando así de una vez el doble sistema de coordenadas - real y simbólico- por el que debe regirse el lector. Como acabo de señalar, el científico ha sido capaz de animar, con ayuda de sus lentes de aumento y la alquimia — ¡otra vez el motivo del Sandmann! - a la princesa que dormía en el cáliz de un tulipán, aunque para ello haya sido necesaria la colaboración de Maese Pulga, quien, al picarla, la libera de un trombo producido por el principio negativo representado por el Príncipe de las sanguijuelas ${ }^{42}$. En ningún mo-

42 En resumen, la ciencia está muy bien — parece pensar Hoffmann — pero conviene no olvidar que la vida y la muerte dependen exclusivamente de la naturaleza. 
mento queda claro que esta manipulación de la naturaleza tenga fines más o menos espirituales; lo que sí está claro es que el holandés sabe usar sus instrumentos con una «óptica» empresarial: recuérdese el espectáculo público mencionado, para el que emplea lo que Hoffmann denomina Nachtmikroskop - «microscopio nocturno»-, término con el que parece subrayar el aspecto negativo del verdaderamente existente Sonnenmikroskop, o microscopio solar: un instrumento, pues, que recuerda al «fantascopio» de Robertson al que de pasada me referí en el artículo precedente ${ }^{43}$. En la misma dirección apunta la información según la cual este Leeuwenhoek literario habría ganado mucho dinero comerciando con microscopios ${ }^{44}$, lo que le convierte en una especie de pariente de Coppola. Pues bien: Leeuwenhoek —el Leeuwenhoek históricoes, precisamente, una de las figuras que Hartmuth Böhme elige para poner a prueba, desde una perspectiva original, el Welt des Auges de Goethe ${ }^{45}$. Y lo que resulta de este examen es extraordinariamente valioso para hacer justicia al supuesto «cuento» de Hoffmann, así como a los otros relatos que nos han ocupado a lo largo de estos dos trabajos.

A juicio del profesor alemán, Leeuwenhoek y Hooke son los más conspicuos representantes de la nueva forma de hacer ciencia propugnada por la institución más prestigiosa de su tiempo: la Royal Society, a la que ambos participaron sus descubrimientos. De ese nuevo estilo es emblema el que la propia sociedad ostenta, que incluye un microscopio, un telescopio y la frase «nullius in verbo» ${ }^{46}$. Difícil será proclamar de una manera más explícita e inequívoca la primacía del sentido de la vista: Pero esta primacía representa todo lo contrario del Welt des Auges goetheano; pues, para la teoría de la visión del «Júpiter de Weimar», cuando se abandona el mundo del ojo se entra de lleno en un terreno peligroso: el de la «metafísica de los fenómenos». Se incurre en esta metafísica cuando se sobrepasa «lo que es conforme a nuestros sentidos, así en lo grande como en lo pequeño» ${ }^{47}$.

Precisamente esto es lo que, con determinación inquebrantable, se plantea la ciencia moderna, construyendo una nueva legalidad científica que, teniendo una base eminentemente sensorial, desconfía de los sentidos tal como los crea la naturaleza. Lo que ellos perciben es a menudo apariencia, y por ello necesi-

\footnotetext{
$43 \mathrm{http} / /$ gutenberg.spiegel.de/?id=5\&xid=582\&kapitel=5\&cHash=71a755b617floh02a \#gb found (Consultada el 19-VII-2007) (p. 5).

44 Ibíd.

45 BöHME (2003), pp. 372-389.

46 BöHME (2003), p. 370.

47 BöHME (2003), pp. 359-360.
} 
tan equiparse de los productos de la técnica para superar sus límites: de aquí la glorificación del microscopio y el telescopio. Esta nueva manera de observar la naturaleza, técnicamente mediatizada, abre, desde luego, cuatro nuevos campos de investigación que el profesor alemán enumera como sigue: «la apertura y desmembramiento del opaco interior del cuerpo», «la exploración del mundo macroscópico mediante el descubrimiento del telescopio», «el mundo subliminal del microscopio» y «la representación experimental del vacío», cuatro territorios hasta entonces inaccesibles a los sentidos ${ }^{48}$. Apenas es preciso recordar que el primero de estos dominios, que lo es también en la perspectiva cronológica, es el que ha puesto en marcha la creatividad hoffmanniana en el tema que nos ocupa, así como mi propia capacidad de reflexión. Desde una perspectiva muy diferente, y sin referirse a él - no olvidemos que su referencia es Goethe-Böhme comparte la crítica de Hoffmann acusando a los microscopistas del Barroco, entre los que destaca a Leeuwenhoek y Hooke, de «fundamentalismo microscópico» ${ }^{49}$, demostrando que sus observaciones microscópicas se vieron modificadas en la representación gráfica que de ellas hacían, directamente o con la ayuda de dibujantes ${ }^{50}$; y precisamente esta modificación de lo observado es lo que, a través del dibujo publicado en una revista científica, alcanza valor de ley; por ejemplo, los homúnculos del esperma «vistos» por Leeuwenhoek ${ }^{51}$. Y no es sólo la inanidad de semejantes «descubrimientos», vista en la perspectiva del presente, lo que permite a Böhme hablar de fundamentalismo y de sueños de la razón; pues, como señala, quien tiene ocasión de observar hoy la luna con un telescopio como el de Galileo no observa lo mismo que observó él ${ }^{52}$. Su conclusión, demoledora para la episteme barroca - y para una historia de la medicina y de la ciencia menos crítica con ella que con otras igualmente especulativas - queda formulada en una frase: «el microscopio no nos permite ver solamente lo invisible, sino también lo imaginario» ${ }^{53}$.

En esta perspectiva nos interesa sobre todo lo que refiere acerca de Leeuwenhoek, por ser éste autor el objetivo de los ataques de Hoffmann. Además

\footnotetext{
48 BÖHME (2003), pp. 366-367

49 BÖHME (2003), p. 372.

50 Al parecer los objetos de experimentación de Leeuwenhoek eran a menudo manipulados numerosas veces hasta alcanzar el grado de elaboración necesario para su presentación en público. BÖHME (2003), pp. 386-387.

51 BÖHME (2003), p. 375.

52 BÖHME (2003), p. 372.

53 BÖHME (2003), p. 377.
} 
de lo ya señalado sobre su papel en la teoría animalculista de la reproducción humana ${ }^{54}$, que tan importante resultó para la defensa del preformacionismo, retrógrado desde nuestros conocimientos actuales sobre la materia y oportunísimo para la religión de la época - la religión, esa enemiga irreconciliable para los científicos más «duros»-, Böhme se detiene en una polémica que sostuvo con Athanasius Kircher en el tema de la reproducción de... ¡las pulgas! (¿Tendrá esto que ver con su elección por parte de Hoffmann, así como la del personaje que da nombre al relato?). «La pulga - escribe nuestro autor - se muestra a los ojos de Leeuwenhoek como un auténtico maníaco sexual (...) Las orgías sexuales de las pulgas son pruebas bienvenidas contra la autoridad romana de Athanasius Kircher ${ }^{55}$. O sea, nada de observación pura desvinculada de la ideología. Más aún, ésta última limita, hasta provocar el error, la capacidad de juicio del investigador. «En cierto sentido - concluye Böhme - el empirismo de Leeuwenhoek se hace dogmático, propiciando la victoria de subterfugios, fantasmas e imaginaciones ${ }^{56}$.

Pues bien: éste es el adversario de Peregrinus Tyss, el explotador de Maese Pulga y su pueblo y el carcelero de la princesa Gamaheh, transmutada en la insustancial Dörtje Elverdink. Y este otro a quien vemos imaginando y escribiendo esta historia es ese Hoffmann ante cuyo nombre el casi deificado consejero áulico de la corte de Weimar arrugaba despectivamente la nariz, paradójicamente convertido en paladín de su Welt des Auges. Por cierto que, a mi parecer, el combate de Hoffmann con Leeuwenhoek alcanzó un resultado bastante mejor que el de Goethe con Newton en la monumental Farbenlehre.

Una vez explicitado todo esto que el lector de Meister Floh no suele conocer, volvamos al relato. Hagámoslo a través de ese resucitado del que acabamos de saber tantas cosas. Ya ha quedado señalado que Leeuwenhoek sabe sacar partido - económico- de sus descubrimientos y de sus aparatos. Pero para él la fortuna material no lo es todo: necesita también la fama, como reconoce ante el estudiante Pepusch: «había otras muchas cosas en juego (...) a las que no podía renunciar sin hacerlo al mismo tiempo a su propia razón de ser, a su vida misma» ${ }^{57}$. Seguramente es por eso, y no por razones económicas, por las que había terminado disputando con Swammerdamm, «hecho

54 DARmon, P. (1977), Le mythe de la procréation à l'âge baroque, París, Société nouvelle des Editions J.J. Pauvert, p. 68. Sobre el animalculismo en general, pp. 67-89.

55 BÖHME (2003), p. 377.

56 BÖHME (2003), p. 383.

$57 \mathrm{http} / /$ gutenberg.spiegel.de/?id=5\&xid=582\&kapitel=5\&cHash=71a755b617floh02a\#gb found (p. 5). 
tanto más corriente entre los sabios cuanto mayor es su ciencia» ${ }^{58}$. Desde este punto de vista se comprende mejor su afán de posesión exclusiva de su homúnculo - Dörtje/Gamaheh - , de quien espera además la resolución definitiva de un enigma - la existencia de un carbunclo del que habla la historia mágica a la que pertenece la propia princesa Gamaheh - que, en su caso, debe desembocar en la posesión de la joya; pues el relato alegórico queda, para él, reducido a la farragosa descripción de una realidad material que la ciencia debe elucidar. Naturalmente, el carbunclo - como el relato de hadas en su conjunto - representa una conquista espiritual que no está reservada al microscopista, sino al ingenuo Peregrinus, ayudado por el conocimiento de los seres humanos que le brinda la lentilla de maese Pulga.

A través de este ingenio óptico tan poco científico asistimos a una exposición de la filosofía de Hoffmann, que no es otra, a mi parecer, que la del $\mathrm{Na}$ turphilosoph Gotthilf Heinrich von Schubert. Es bien conocida la devoción que el escritor sentía por esta filosofía de la naturaleza ${ }^{59}$. En una ocasión en que Peregrinus emplea la lente sobre Dörtje estando ésta desmayada contempla sus pensamientos bajo la forma de una red de «venas» y de «hilos argentados finísimos»; y las imágenes que descubre en estos deslumbrantes circuitos presentan una metamorfosis de formas de la naturaleza que recuerdan extraordinariamente lo que Schubert plantea en su Symbolik des Traumes, tanto más cuanto que maese Pulga dice que esas imágenes son los pensamientos que se tienen en sueños ${ }^{60}$. Como, por otra parte, la muchacha está desmayada, creo poder afirmar que esas imágenes oníricas pertenecen a la «parte Gamaheh» de su existencia, y que tal es la intención del escritor al redactar este fragmento. Pero, además de reiterar su admiración por esta filosofía, Hoffmann aprovecha la ocasión que le brinda su relato para manifestarse en contra de los aspectos a su juicio negativos del ascendente espíritu científico. Por más que la cita pueda resultar un poco larga, prefiero transcribirla para

$58 \mathrm{http} / /$ gutenberg.spiegel.de/?id=5\&xid=582\&kapitel=6\&cHash=71a755b6172\#gb_found (p. 6).

Esta actitud configurará el tema de un breve relato, bastante poco conocido, aunque interesantísimo, de Hoffmann, titulado Haimatochäre.

59 He tratado el tema en otras publicaciones: el artículo, ya citado en n. 30, sobre $\mathrm{El} \mathrm{cal-}$ dero de oro, y también en MonTIEL, L. (2003), Primera mirada sobre el lado oscuro del magnetismo: 'El magnetizador', de E.T.A. Hoffmann. En: Montiel, L., GonZAlez DE PABLO, A. (eds.), En ningún lugar. En parte alguna. Estudios sobre la historia del magnetismo animal y del hipnotismo, Madrid, Frenia, pp. 143-170.

60 Cfr. SCHUBERT, G.H. (1999), El simbolismo del sueño. Edición y estudio preliminar de Luis Montiel, Barcelona, MRA, p. 55. 
permitir al lector hacerse cargo directa y plenamente del pensamiento de Hofmann:

«En cuanto a vosotros, pobres locos, infortunado Swammerdam, y tu, lamentable Leeuwenhoek, vuestra vida entera no ha sido más que un error interminable. Habéis pretendido investigar los secretos de la naturaleza sin sospechar su significación profunda. Habéis osado penetrar en su laboratorio e intentado sorprenderla en su misterioso trabajo. Esperabais lograr entrever impunemente los terribles secretos de esas profundidades espantosas que ninguna mirada humana podría descifrar (...) Vuestro corazón ha permanecido inerte y sin vida. Nunca un amor verdadero ha inflamado vuestro ser, nunca las flores ni los insectos de alas ligeras y multicolores os han dirigido dulces palabras. Creíais contemplar con recogimiento y con piadosa admiración los grandes misterios sagrados de la naturaleza, pero esforzándoos —empresa criminal- en analizar las causas profundas de esos milagros, habéis aniquilado ese recogimiento. Y el conocimiento al que aspirabais no fue, a partir de ese momento, más que una vana apariencia que os ha engañado como lo habría hecho con niños curiosos e indiscretos» ${ }^{61}$.

\section{Conclusión: un Prometeo de estatura humana}

Sería tal vez precipitado despachar estas frases de Peregrinus Tyss, ahora más que nunca portavoz de Hoffmann, con un par de dicterios sobre el carácter retrógrado del pensamiento romántico, como resultaría injustificado - $\mathrm{e}$ injusto- suscribir sin más todos los aspectos de este discurso descalificador del empeño científico. Puede, desde luego, situársele en el entorno intelectual - un entorno de larga duración - acotado por Roger Shattuck en su cautivador Conocimiento prohibido ${ }^{62}$. Pero además creo que se le debe contextualizar en la perspectiva que el propio Hoffmann adopta unas páginas más atrás, cuando, precisamente, se refiere a lo prometéico, que tan presente ha estado en estos dos trabajos «sobre máquinas e instrumentos». Esto es lo que a este respecto piensa Hofmann, cercana ya su muerte:

«Habría mucho que decir (...) sobre la chispa celeste que hizo brotar Prometeo, chispa que enciende en el acto del amor esta verdadera comunión espiritual entre

$61 \mathrm{http}: /$ gutenberg.spiegel.de/?id=5\&xid=582\&kapitel=20\&cHash=71a755b617floh07a\#gb found (p. 20).

62 Shattuck, R. (1998), Conocimiento prohibido. De Prometeo a la pornografía, Madrid, Taurus. Edición original en inglés: Forbidden Knowledge. From Prometheus to Pornography, New York, St. Martin's Press, 1996. 
los dos sexos, en que se manifiesta el dualismo necesario presente en la naturaleza. Pues si ocurriera que esta chispa encendida por Prometeo se propagara hasta abrazar la antorcha del dios del matrimonio para hacer de ella una luminosa y potente candela doméstica cerca de la cual se pueda leer, escribir, tricotar o coser (...) las cosas no harían más que seguir el curso normal que tienen aquí abajo. Un amor de este modo divino está, desde luego, muy en su lugar en un papel sublimemente poético, y la mejor alabanza que puede hacérsele es que no tiene nada de quimera vana, sino que produce, al contrario, efectos muy tangibles, como pueden atestiguar muchas personas que a causa suya han conocido alegrías o sufrimientos» ${ }^{63}$.

Seres humanos, y no homúnculos, es lo que, a juicio de Hoffmann, debe producir este Prometeo que respeta el esencial dualismo de la naturaleza. Con él pretende enterrar, no menos que al Knarrpantti sobre el que, con justicia, tanta tinta ha corrido, a ese otro Prometeo de Coppelius y de los Leeuwenhoek y Swammerdamm de Meister Floh. No corren buenos tiempos para el dualismo, y los empeños de muchos científicos presentan una inquietante similitud — mutatis mutandis, como diría mi querido maestro Pedro Laín - a los del inquietante personaje del Sandmann. Verdad es que también existe alguna postura dualista — la que gobierna la teoría del diseño inteligentesobre la que nuestro autor, si viviera entre nosotros, caería como un ave de presa con especial júbilo. Pero no se trata de plantear un ambicioso $-\mathrm{y}$ probablemente estéril - debate sobre monismo y dualismo, sino de quedarse en el nivel mucho más inmediato de los hechos - y sí; también de los valoresentendiendo que el mensaje de Hoffmann sigue vivo y merece ser tenido en cuenta, más allá de las certidumbres del actual pensamiento científico y de la eficacia de muchos de sus logros.

Agradecimientos: Al Prof. Jesús González Requena, por el generoso envío de sus publicaciones sobre el tema «lo siniestro»; al Prof. Thomas Müller por su ayuda en la recuperación del texto de Goethe sobre el Welt des Auges, así como en el manejo de algunos términos alemanes; y a la Prof. María Isabel Porras por su atenta revisión del manuscrito.

Fecha de recepción: 16 de marzo de 2007.

Fecha de aceptación: 30 de octubre de 2007.

$63 \mathrm{http} / /$ gutenberg.spiegel.de/?id=5\&xid=582\&kapitel=20\&cHash=71a755b617floh07a\#gb found (p. 20). 